\title{
The Integration of the Imaginary in Websites
}

\author{
Rim Gharbi Mrabet ${ }^{1}$ and Jamel Eddine Gharbi ${ }^{2}$ \\ ${ }^{1}$ University of Carthage and University of Montpellier, Nabeul, Tunisia \\ ${ }^{2}$ University of Jendouba, Tunis, Tunisia
}

Correspondence should be addressed to: Rim Gharbi Mrabet; rimagharbi@gmail.com

Received date: 23 April 2015; Accepted date: 11 July 2015; Published date: 27 October 2015

Copyright (C) 2015. Rim Gharbi Mrabet and Jamel Eddine Gharbi. Distributed under Creative Commons CC-BY 4.0

\begin{abstract}
Although communication strategies are a widely studied component of electronic commerce, much of the literature on the integration of imaginary in websites has remained loosely connected and key questions remain unanswered. The aim of this paper is to determine the influence of the integration of imaginary in the web site on the effectiveness of Internet Communication. To achieve this goal, experimentation was carried out on 320 visitors. The key insight from our study is that the integration of imaginary in websites has a significant impact on loyalty.
\end{abstract}

Keywords: Imaginary, web site, loyalty, flow state.

\section{Introduction}

With the emergence of high flow wireless network technologies, the global advertising industry's interest in using this medium as a means of marketing communication is rising. The electronic commerce is one of the most popular media which allows/enhances mobile marketing campaigns. These companies consider the integration of the imaginary in the website as a new trend that allows them to attract the web site's visitors, to catch their attentions, and to follow a favorable behavioral approach such as a positive attitude towards the product or service, the purchase, or the loyalty.

\section{The main body of the paper}

\section{Literature review}

This concept of imaginary has historically been considered as having an important role in all forms of thinking (Thomas, 1998). Several researchers and theorists sought to understand how people use their imagination to manifest the imaginary (Iser, 1993, Kearney, 1988). Holbrook and Hirschman (1982) were pioneers in conducting research dealing with the imaginary of consumers by highlighting the value of the recognition of consumer fantasies and mental imagery. Other researchers have also noted the importance of the imaginary, such as Sherry (1990) who

Cite this Article as: Rim Gharbi Mrabet and Jamel Eddine Gharbi (2015)," The Integration of the Imaginary in Websites", Journal of Internet and e-Business Studies, Vol. 2015 (2015), Article ID 254814, DOI:10.5171/2015.254814 
stated that the use of imaginary is an essential activity in consumption. Similarly, Scott (1990) conducted several studies that focused on the consumer. He stressed that "the work of the imagination is clearly an important aspect of the mental experience of a person". Recently, there is a growing recognition of the imaginary or synonymously: "imagination" among researchers who conducted studies around the consumer. They argue that the imagination plays an important role in the consumption experience. Pefialoza (2001), in an interesting study of cultural production, highlights how consumers use the imagination to create meanings. Castoriadis (1975) argues that imagination is a more appropriate conceptualization to study individuals in modern society. For Castoriadis, the focus of commercial modern society on creating new products to meet new needs rather than functional basis needs reveals the considerable influence of the imagination. Fantasy helps producers to create new products. It also helps consumers to determine and specify what is desirable and to create fashion. Brett (2004) described the dynamics of how consumers generate fantastic fantasy during consumption. Several companies have also used the imagination in the context of Internet communication to lead visitors to behave in a favorable way such as generate a positive attitude toward the product or service, purchase or loyalty. In addition, the atmospheric commercial sites models of Baker (1986) and Bitner (1992) took into account the cognitive, emotional, and sensory dimensions of the retail space. However, they neglected the imaginary and symbolic dimensions. These dimensions have been proposed by several authors. Ouvry and Ladwein (2006) considered these dimensions as important dimensions to improve the quality of the experience in the retail space. Our research aims to fill this gap. Moreover, the state of flow has been proposed as a reliability indicator of the browsing experience in a commercial website (Hoffman and Novak, 1997). This concept represents an immersion condition in the site. Flow state could be described as an imaginary absorption of the individual into the content of the site and/or in the browsing activity of this user. Previous research focused on environmental factors that led to this optimal browsing experience. However, they did not study the imaginary history of the site.

\section{Research question}

Our research aims to study the influence of the imaginary in the web site on achieving the state of flow and loyalty. We try to answer the following question: What is the impact of the integration of the imaginary in the website on loyalty to the website? Thus, this research hopes to provide a theoretical and empirical understanding of how companies can improve their loyalty to the websites by integrating imaginary. The goal of our research is based on three components: The first component represents a highlight of several variables that generate a positive behavior approach towards the site through the integration of imaginary. The second component consists in providing practitioners with a number of recommendations that can be followed to ensure better communication via the Internet. The last component corresponds to insuring a new solution to enhance and consolidate loyalty behavior through the integration of imaginary in the web site. Our conceptual model is presented as follows: 


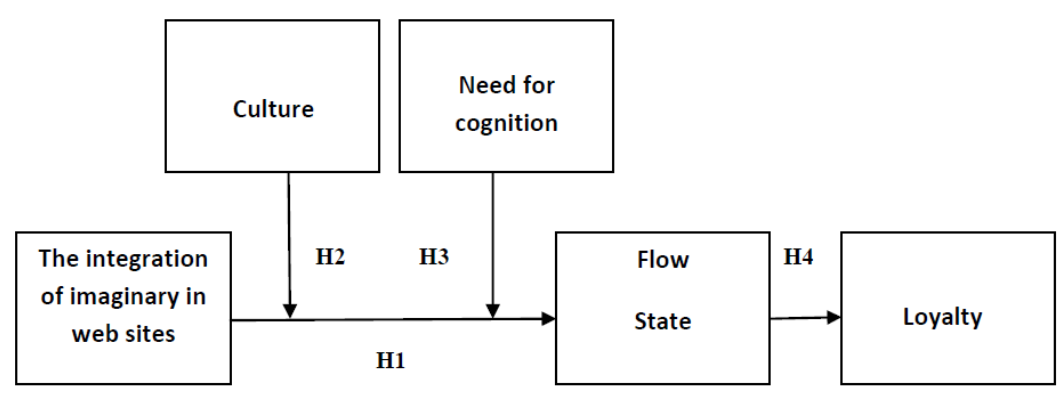

Figure 1-The conceptual Model

\section{Research design and methodology}

In the following table, we will present the experimental methodology and the sampling process in order to investigate the proposed relationships. Furthermore, we will justify our choice of diverse scales of measurement.

Table 1: Measurement scales

\begin{tabular}{|l|l|l|}
\hline Variables & $\begin{array}{l}\text { Measurement } \\
\text { scales } \\
\text { \& Authors }\end{array}$ & Due to the choice of measurement scale \\
\hline $\begin{array}{l}\text { The Revised } \\
\text { Extroticism- } \\
\text { Opennession- } \\
\text { Personality } \\
\text { Inventor:NEO } \\
\text { PI-R; Costa } \\
\text { and McCrae } \\
\text { (1992) }\end{array}$ & $\begin{array}{l}\text { This scale includes various aspects of the imagination such as: the loose of } \\
\text { thoughts, the level of imagination, and the level of fantasy... The } \\
\text { integration of these aspects makes this scale the most suitable to our } \\
\text { context and closer to our theoretical definitions. } \\
\text { The reliability of this scale is good and (reliability = 0, 83) and therefore, } \\
\text { it is considered as the most reliable scale. } \\
\text { This measurement scale has a good parsimony since it includes only 10 } \\
\text { items. }\end{array}$ \\
\hline Flow State & $\begin{array}{l}\text { The flow } \\
\text { measurement } \\
\text { scale of Pearce } \\
\text { et al (2004) }\end{array}$ & $\begin{array}{l}\text { This scale covers the essential dimensions of the flow, which are: Control, } \\
\text { interest, enjoyment, challenge and skills. Therefore, this scale agrees with } \\
\text { our theoretical definitions. } \\
\text { It has a good reliability and parsimony since it includes only 13 items. } \\
\text { It includes the main dimension which represents the basic idea of state of } \\
\text { flow's concept: the perception of balance between the challenges and } \\
\text { skills. }\end{array}$ \\
\hline Culture & $\begin{array}{l}\text { Measurement } \\
\text { scale of } \\
\text { culture; } \\
\text { OReilly et al. } \\
\text { (1991) }\end{array}$ & $\begin{array}{l}\text { This scale encompasses the main personality's traits; it is therefore the } \\
\text { most appropriate scale to our study. } \\
\text { Dimensions' reliabilities of the scale are good; therefore, the overall } \\
\text { reliability of the scale is also good. }\end{array}$ \\
\hline
\end{tabular}




\begin{tabular}{|l|l|l|}
\hline $\begin{array}{l}\text { Need for } \\
\text { cognition }\end{array}$ & $\begin{array}{l}\text { Measurement } \\
\text { scale of the } \\
\text { need for } \\
\text { cognition; } \\
\text { Petty, } \\
\text { Cacioppo et al., } \\
\text { (1984) }\end{array}$ & $\begin{array}{l}\text { This scale is composed of 34 items measured on the five-point Likert scale: } \\
\text { from "strongly disagree" to "strongly agree". Indeed, it fits the aim of our } \\
\text { research which is to make a comparison between individuals. The } \\
\text { Cronbach's alpha of this scale is: 0.90. In fact, it is the short-form of the } \\
\text { scale of Cacioppo and Petty (1982). The Alpha of Coronach of Cacioppo et } \\
\text { al's scale (1982) is 0.91. The correlation between the scales is 0.95. }\end{array}$ \\
\hline Loyalty & $\begin{array}{l}\text { The Overall } \\
\text { Loyalty Scale } \\
\text { of Oliver } \\
\text { (1997) }\end{array}$ & $\begin{array}{l}\text { This scale includes/encompasses all dimensions of loyalty: cognitive loyalty, } \\
\text { affective loyalty, affective loyalty, and action Loyalty. So, it is the most } \\
\text { appropriate measurement scale. It has a good reliability: (The Alpha of } \\
\text { Cronbach = 0, 8). It measures the overall loyalty of consumers who are } \\
\text { exposed to websites. Thus, it is the most appropriate scale. }\end{array}$ \\
\hline
\end{tabular}

\section{Methodology and data collection}

The objective of this research is to test the impact of the integration of the imaginary in websites on achieving flow state and loyalty to the web site. Therefore, we will compare results of two separate parts of our target. These results are obtained after the exposure of the first part of our target to a site including the imaginary and the other part to a site that does not include this concept. Thus, we will assign questionnaires to a population composed mainly of students. We justify our choice by the fact that students are a homogeneous and representative sample of the target population. They also represent potential target consumers for "Nike shoes" which is the product of our study. Students are also potential users of websites, especially sites associated with Nike products. Our sample is composed of 320 students, $82.2 \%$ of them are between 20 and 29 years; $61.3 \%$ are male; $92.8 \%$ are single; $26.3 \%$ spend between 100 dinars and 150 dinars per month; $21.6 \%$ spend between 150 dinars and 200 dinars per month; $21.6 \%$ also spend a sum above 200 dinars monthly; 19.4\% spend between 50 Dinars and 100 dinars per month and only $11.3 \%$ spend a sum of money less than 50 dinars per month. These results indicate that the highest percentage of respondents are those who spend more than 100 dinars per month, which allows us to consider them as potential consumers of Nike products, if we take into account the criterion of average monthly expenditure as an effective indicator. This indicator allows us to conclude that our respondents may be considered as potential buyers and consumers of Nike products. Our sample was divided into two equal parts: the first part is composed of 160 respondents who were exposed to the first site incorporating imagination of the brand "Nike"; and the second part is composed of 160 other respondents who were exposed to the second classic site of the brand "Nike" which does not include imagination. We asked them to complete the first part of the questionnaire which included scales measuring variables of culture and the need for cognition. These respondents were then exposed to one type of website, and then they were asked to complete the rest of the questionnaire and to answer to questions related to these variables: the imagination, the state of flow and loyalty to the website. The experiment lasted 15 minutes when respondent is exposed to regular site and 20 minutes when they are exposed to the second site incorporating the imagination. Respondents of the site integrating imagination were exposed to the homepage of the official website of Nike: http://www.nike.com. We asked them to watch three videos integrating imaginary and included in the site: the sequence of Nike +; Nike evolution (http://www.pub_nike_evolution.mov) and Nike football (http://www.pub_Nike_football_clement261wat.tv). Then, we asked to click on the link and see Nike Store, Nike products for men and women according to their preferences. 
We chose to focus only on "Nike shoes" to facilitate the experimental conditions and to ensure the same exposure conditions for all respondents. The respondents were exposed to the page "Nike store" and "Nike shoes" with different offers and prices for these products. Regarding the second website, the respondents were invited to visit the site directly on this address: http://www.store.nike.com. Then, they were exposed to the same Nike shoes, offers and prices for these products. Afterward, we made a comparison between the results of experiments conducted on respondents exposed to the site that includes imagination and respondents exposed to the classic site that does not incorporate imagination.

Results and discussion

We tried to empirically test our conceptual model by testing hypotheses. Therefore, we used the linear regression.

\section{The effect of the type of site on flow state}

\subsection{Checking the impact of the type of site on the state of interest}

The interest in the website is one of the dimensions of the state of flow. Relying on the results, we can say that the relationship between the type of website and interest in the site is significant. Indeed, the check of the model gave an overall R-square of 0,071 . This means that $7,1 \%$ of the total variance of interest to the site is explained by the type of site. This result is confirmed by the test Fisher F, which is equal to 24,402 with a significance of 0,000 . Relying on the graph of estimated marginal averages of the interest to the site, we found out that the estimated marginal averages increase significantly from the site that does not integrate the imagination to the site that integrates the imagination, that is to say the interest in the website increases significantly from a site which does not integrate imagination to the site incorporating the imagination. Hence, we can conclude that the integration of the imagination in the website has a positive effect on interest in the web site, which is one of the dimensions of the state of flow.

\subsection{Checking the impact of the type of site on the enjoyment}

The enjoyment is one of the 3 dimensions of the state of flow. The results showed that the correlation between the type of website and the enjoyment is significant. Indeed, the check of the model gave an overall R-square of 0,071 . This means that $7,1 \%$ of the total variance of the enjoyment is explained by the type of the site. This result is confirmed by the test Fisher $\mathrm{F}$, which is equal to 5,545 with a significance of 0,019 . Basing on results presented in the chart of estimated marginal averages of the enjoyment of the site, we found out that the estimated marginal averages increase significantly from the site that does not integrate the imagination to the site that integrates the imagination, that is to say that the enjoyment of the website increases significantly from a site which does not integrate imagination to the site incorporating the imagination. We can safely conclude that the integration of the imagination in the website has a positive effect on enjoyment of the web site, which is one of the dimensions of the state of flow.

\subsection{Checking the impact of the type of the site on the challenges and skills of the state of flow}

The challenges and skills are the third dimensions of the state of flow. Relying on the results, we can say that the relationship between the type of the website and challenges and skills is not significant. Indeed, checking of the model gave an overall $\mathrm{R}$-square of 0,01 . This means that $1 \%$ of the total variance of challenges and skills is explained by the type of site. This result is confirmed by the test Fisher F, which is equal to 3,326 with a significance of 0,069 . Relying on the graph of estimated marginal averages of challenge and skills, we found that the estimated marginal averages increase significantly from the site that does not integrate the imagination to the site that 
integrates the imagination, that is to say that the challenge and skills increases significantly from a site which does not integrate imagination to the site incorporating the imagination. Consequently, we conclude that the integration of the imagination in the website has no effect on web users' challenges and skills.

Our first hypothesis, which states that the integration of imagination in the website has an effect on the state of flow, is confirmed. This positive impact is based on results and stressed that the integration of imagination in the website can increase interest and enjoyment provided by the website. The result is consistent with results published by Hoffman and Novak Duhachek (2002) who consider that two different activities with different natures require two different websites in terms of content and design to achieve the state of flow. Their research is based on experiential activities and goal oriented activities (such as research or shopping): these activities require two different types of websites in terms of content and design to achieve the state of flow. Csikszentmihalyi (1982) also confirmed this result in his work based on the state of flow in web sites' context. This result can be useful to managers of products sold on commercial sites, especially regarding the development of the content of their sites and the integration of the imaginary in the website to reach the state of flow. Moreover, the validation of this hypothesis has allowed us to verify and confirm experimental conditions of our study.

\section{The effect of the need for cognition on the relationship between the integration of imaginary in web site and flow state}

To test the effect of need for cognition on the relationship between the integration of the imaginary in the website and the state of flow, we checked the effect of need for cognition on various dimensions of flow: interest in the website, enjoyment and challenges and skills.

2.1. Checking the impact of the Need for cognition on the relationship between the integration of imaginary in web site and Interest in the web site

Relying on the results obtained by our analysis, we can conclude that the effect of need for cognition on the relationship between the type of site and the interest in the site is significant. The model has an overall R-square equal to 0.119 , which allows us to deduce that $11,9 \%$ of the variance in the relationship between the type of site and the interest in the web site is explained by the level of need for cognition. Moreover, statistics obtained reveal that the effect of low need for cognition on the relationship between the type of site and the interest in the site is significant, unlike the effect of high need for cognition on the relationship between the type of site and interest in the website, which is not significant. 
Table 2: Summary of results of the effect of need for cognition on the relationship between the integration of the imaginary in the website and interest in the website

\begin{tabular}{|c|c|c|c|}
\hline The relationship & $\begin{array}{l}\text { Effect of need for } \\
\text { cognition on the } \\
\text { relationship } \\
\text { between the type of } \\
\text { site and the interest } \\
\text { in the site }\end{array}$ & $\begin{array}{l}\text { Effect of low need for } \\
\text { cognition on the } \\
\text { relationship between } \\
\text { the type of site and the } \\
\text { interest in the site }\end{array}$ & $\begin{array}{l}\text { Effect of high need for } \\
\text { cognition on the } \\
\text { relationship between } \\
\text { the type of site and the } \\
\text { interest in the site }\end{array}$ \\
\hline F Fisher & 8,478 & 5,515 & 2,992 \\
\hline Significance F & 0,000 & 0,004 & 0,052 \\
\hline $\begin{array}{c}\text { Characteristic of } \\
\text { estimated } \\
\text { marginal } \\
\text { averages }\end{array}$ & $\begin{array}{l}\text { Significant growth } \\
\text { from a site which } \\
\text { does not integrate } \\
\text { imagination to the } \\
\text { site incorporating } \\
\text { imagination }\end{array}$ & $\begin{array}{l}\text { Significant growth from } \\
\text { a site which does not } \\
\text { integrate imagination to } \\
\text { the site incorporating } \\
\text { imagination }\end{array}$ & $\begin{array}{l}\text { Significant growth from } \\
\text { a site which does not } \\
\text { integrate imagination to } \\
\text { the site incorporating } \\
\text { imagination }\end{array}$ \\
\hline
\end{tabular}

With reference to the table above, we can safely say that the integration of imagination in the website has a positive effect on the interest in the site, on high need for cognition and on low need for cognition; but the growth of interest in the site is higher for people with a high level of need for cognition than for those with a low level of need for cognition.

2.2. Effect of need for cognition on the relationship between the integration of imaginary in the website and the enjoyment

The enjoyment offered by the website is the second dimension of the state of flow. The results reveal that the effect of need for cognition on the relationship between the type of site and enjoyment provided by the site is significant. The model has an overall Rsquare equal to 0.089 . We can, therefore, assume that $8.9 \%$ of variance of the relationship between the type of site and enjoyment provided by this website is explained by the level of need for cognition. In addition, statistics reveal that the effect of low need for cognition on the relationship between the type of site and the enjoyment provided by this site is significant, unlike the effect of the need for high cognition on the relationship between the type of site and enjoyment provided by this site, which is not significant. 
Table 3: Summary of the results of the effect of need for cognition on the relationship between the integration of the imaginary in the website and the enjoyment provided by the site

\begin{tabular}{|c|c|c|c|}
\hline The relationship & $\begin{array}{c}\text { Effect of need for } \\
\text { cognition on the } \\
\text { relationship } \\
\text { between the type of } \\
\text { site and Enjoyment }\end{array}$ & $\begin{array}{c}\text { Effect of low need for } \\
\text { cognition on the } \\
\text { relationship between } \\
\text { the type of site and } \\
\text { enjoyment provided by } \\
\text { the site }\end{array}$ & $\begin{array}{c}\text { Effect of high need for } \\
\text { cognition on the } \\
\text { relationship between } \\
\text { the type of site and } \\
\text { enjoyment }\end{array}$ \\
\hline F Fisher & $\mathbf{6 , 1 7 0}$ & 11,230 & 1,415 \\
\hline $\begin{array}{c}\text { Characteristic of } \\
\text { estimated } \\
\text { marginal } \\
\text { averages }\end{array}$ & $\begin{array}{c}\text { Significant growth } \\
\text { from a site which } \\
\text { does not integrate } \\
\text { imagination to the } \\
\text { site incorporating } \\
\text { imagination }\end{array}$ & $\begin{array}{c}\text { Significant growth from } \\
\text { a site which does not } \\
\text { integrate imagination to } \\
\text { the site incorporating } \\
\text { imagination }\end{array}$ & $\begin{array}{c}\text { Significant growth from } \\
\text { a site which does not } \\
\text { integrate imagination to } \\
\text { the site incorporating } \\
\text { imagination }\end{array}$ \\
\hline
\end{tabular}

With reference to the table above, we can say that the integration of imaginary in the website has a positive impact on the enjoyment provided by the website, for both people with a low need for cognition and for those with a high need for cognition.

2.3. Effect of the need for cognition on the relationship between the integration of imaginary in the website and the challenges and skills

Challenges and skills provided by the website is the third dimension of the state of flow. The results lead us to conclude that the effect of need for cognition on the relationship between the type of site and the challenges and skills is not significant. The model has an overall R-square equal to 0.023 , which enables us to assume that $2,3 \%$ of the variance in the relationship between the type of site and the challenges and skills is explained by the level of need for cognition. Statistics also reveal that the effect of low need for cognition on the relationship between the type of site and the challenges and skills is significant, similarly for the effect of the high need for cognition on the relationship between the type of site and challenges and skills, which is also significant.

Table 4: Summary of the results of the effect of need for cognition on the relationship between the integration of the imaginary in the website and the challenges and skills

\begin{tabular}{|c|c|c|c|}
\hline The relationship & $\begin{array}{c}\text { Effect of need for } \\
\text { cognition on the } \\
\text { relationship } \\
\text { between the type of } \\
\text { site and the } \\
\text { challenges and skills }\end{array}$ & $\begin{array}{c}\text { Effect of low need for } \\
\text { cognition on the } \\
\text { relationship between } \\
\text { the type of site and the } \\
\text { challenges and skills }\end{array}$ & $\begin{array}{c}\text { Effect of high need for } \\
\text { cognition on the } \\
\text { relationship between } \\
\text { the type of site and the } \\
\text { challenges and skills }\end{array}$ \\
\hline F Fisher & 1,483 & 1,576 & 1,415 \\
\hline Significance F & $\begin{array}{c}\mathbf{0 , 1 9 5}(\mathbf{> 0 , 0 5}): \\
\text { not significant }\end{array}$ & $\begin{array}{c}\mathbf{0 , 2 0 8}(\mathbf{> 0 , 0 5}): \\
\text { not significant }\end{array}$ & $\begin{array}{c}\mathbf{0 , 2 4 5}(\mathbf{0 , 0 5}): \\
\text { not significant }\end{array}$ \\
\hline
\end{tabular}

Rim Gharbi Mrabet and Jamel Eddine Gharbi (2015), Journal of Internet and e-Business Studies, DOI: 10.5171/2015. 254814 
With reference to this table, we can say that the level of need for cognition has no effect on the relationship between the type of site and the challenges and skills. Consequently, we can assert that our second hypothesis, which states that the need for cognition affects the relationship between the integration of the imaginary in the website and the state of flow, is confirmed. This result is also confirmed by the findings obtained by Dahui (2006) which focused on the role of mood and need for cognition on the state of flow. This result is also similar to the findings of Das Echambadi, McCardle and Michael Luckett (2003). These findings may also be used by active practitioners in setting up their business strategies and designing of the content of their websites to increase sales within these web sites.

\section{Effect of culture on the relationship between the integration of the imaginary in the website and the state of flow}

To test the effect of culture on the relationship between the integration of the imaginary in the website and the state of flow, we tested the effect of culture on the different dimensions of flow: interest in the site, enjoyment and challenges, and skills.

3.1. Effect of culture on the relationship between the integration of the imaginary in the site and the interest in the website

Following the experimentation we conducted on our two different websites, and based on results, we can conclude that the effect of culture on the relationship between the type of site and the interest in website is significant. The model has an overall Rsquare equal to 0.092 , which leads us to presume that $9.2 \%$ of the variance in the relationship between the type of site and the interest in the website is explained by the culture of web visitor.

Table 5: Summary of the results of the effect of culture on the relationship between the integration of the imaginary in the website and the interest in the site

\begin{tabular}{|c|c|}
\hline The relationship & $\begin{array}{c}\text { Effect of culture on the relationship between the type of site } \\
\text { and the interest in the website }\end{array}$ \\
\hline F Fisher & 4,501 \\
\hline Significance F & $\mathbf{0 , 0 0 0}$ \\
\hline $\begin{array}{c}\text { Characteristic of } \\
\text { estimated } \\
\text { marginal } \\
\text { averages }\end{array}$ & $\begin{array}{c}\text { Significant growth from the site which does not include } \\
\text { imaginary to the website that integrates the imaginary }\end{array}$ \\
\hline
\end{tabular}

According to this table, we can assume that culture has a moderating effect on the relationship between the type of website and the interest in the website.

3.2. Effect of culture on the relationship between the integration of the imaginary in the site and enjoyment provided by the website
Based on the results of our experiment, we can conclude that the effect of culture on the relationship between the type of site and enjoyment provided by the website is not significant. The model has an overall Rsquare equal to 0.041 , which makes us assume that $4.1 \%$ of the variance in the relationship between the type of site and

Rim Gharbi Mrabet and Jamel Eddine Gharbi (2015), Journal of Internet and e-Business Studies, DOI: 10.5171/2015. 254814 
enjoyment provided by the website is explained by the culture of web visitors.

Table 6: Summary of the results of the effect of culture on the relationship between the integration of the imaginary in the website and the enjoyment provided by the site

\begin{tabular}{|c|c|}
\hline The relationship & $\begin{array}{r}\text { Effect of culture on the relationship between the type of site } \\
\text { and enjoyment provided by the website }\end{array}$ \\
\hline F Fisher & 1,884 \\
\hline Significance $\mathbf{F}$ & $\mathbf{0 , 0 7 2}(\mathbf{> 0 , 0 5 )}$ \\
\hline $\begin{array}{c}\text { Characteristic of } \\
\text { estimated } \\
\text { marginal } \\
\text { averages }\end{array}$ & $\begin{array}{c}\text { Significant growth from the site which does not include } \\
\text { imaginary to the website that integrates imaginary }\end{array}$ \\
\hline
\end{tabular}

According to this table, we can conclude that culture has no moderating effect on the relationship between the type of website and enjoyment provided by the site.

\subsection{Effect of culture on the relationship} between the integration of the imaginary in the website and the challenges and skills

Relying on results of the experiment we conducted on our two different websites, we can conclude that the effect of culture on the relationship between the integration of the imaginary in the website and challenges and skills is significant. The model has an overall R-square equal to 0.071 , which leads us to conclude that $71 \%$ of the variance in the relationship between the type of site and the interest in the website is explained by the culture of the visitor of the site.

Table 7: Summary of the results of the effect of culture on the relationship between the type of site and the challenges and skills

\begin{tabular}{|c|c|}
\hline The relationship & $\begin{array}{c}\text { Effect of culture on the relationship between the type of site } \\
\text { and the challenges and skills }\end{array}$ \\
\hline F Fisher & 3,407 \\
\hline Significance F & $\mathbf{0 , 0 0 2}$ \\
\hline $\begin{array}{c}\text { Characteristic of } \\
\text { estimated } \\
\text { marginal } \\
\text { averages }\end{array}$ & $\begin{array}{c}\text { Significant growth from the site which does not include } \\
\text { imaginary to the website that integrates imaginary }\end{array}$ \\
\hline
\end{tabular}

According to this table, we can conclude that culture has a moderating effect on the relationship between the type of website and the challenges and skills.

Thus, the hypothesis which states that the culture has a moderating effect on the relationship between the integration of the imaginary in the website and the state of flow is confirmed. The study of Luna, Peracchio Dejan (2005) based on the effect of culture on the cognitive aspects of web browsing confirm this result. From a managerial point of view, managers could take into account the cultural differences of individuals in the design of the website content. 
4. The effect of the state of flow on loyalty to the website

In order to test of the effect of the state of flow on loyalty to the website, we tested the effect of the state of flow on the different dimensions of loyalty: cognitive loyalty, affective loyalty and affective loyalty.

Th results of the experiment conducted on the two websites showed that the effect of the state of flow on behavioral loyalty is significant. The model has an overall Rsquared equal to 0.0106 . Hence, we concluded that $10.6 \%$ of the variance of the behavioral loyalty is explained by the flow. Concerning the relationship of the effect of the state of flow on cognitive loyalty, we assert that this relationship is significant. The model has an overall R- square equal to 0.173 , meaning that $17.3 \%$ of the variance in cognitive loyalty is explained by the flow. However, the effect of the state of flow on the emotional loyalty is not significant with an overall R- square equal to 0.13 . Thus, we concluded that $13 \%$ of the variance of emotional loyalty is explained by the state of flow.

Table 8: Summary of the results of the effect of the state of flow on loyalty to the website

\begin{tabular}{|c|c|c|c|}
\hline $\begin{array}{c}\text { The } \\
\text { relationship }\end{array}$ & $\begin{array}{c}\text { Effect of the state of flow } \\
\text { on behavioural loyalty }\end{array}$ & $\begin{array}{c}\text { Effect of the state of flow } \\
\text { on cognitive loyalty }\end{array}$ & $\begin{array}{c}\text { Effect of the state of } \\
\text { flow on affective loyalty }\end{array}$ \\
\hline F Fisher & 12,429 & 22,074 & 15,784 \\
\hline Significance F & $\mathbf{0 , 0 0 0}$ & $\mathbf{0 , 0 0 0}$ & $\mathbf{0 , 0 0 0}$ \\
\hline
\end{tabular}

In the following experiment, we used the Beta coefficient of regression between loyalty and the state of flow to determine the dimensions of the flow state that affect the loyalty to the website and the direction of the relationship between these dimensions and the loyalty to the website.

Regarding behavioral loyalty to the website and following the results of the experiment, we can assume that the Beta coefficient is positive for flow' dimensions: interest in the site, enjoyment provided by the site and the challenges and skills; hence, we confirm the results of the regression. However, we noted that: $\mathrm{t}<1.96$ for the enjoyment and challenges and skills. Thus, we concluded that the direction of the relationship is positive only for the interest in the website.

\section{Table 9: Results of the Beta coefficient of regression between behavioural loyalty and the state of flow}

\begin{tabular}{|c|c|c|c|}
\hline $\begin{array}{c}\text { Dimensions } \\
\text { of flow state }\end{array}$ & Interest in the website & Enjoyment & Skills and challenges \\
\hline B & 0,318 & 0,066 & 0,001 \\
\hline $\mathrm{T}$ & 5,979 & 1,123 & 0,025 \\
\hline $\mathbf{P}$ & 0,000 & 0,217 & 0,980 \\
\hline
\end{tabular}

Concerning cognitive loyalty to the website, and following results of the experiment, we believe that the Beta coefficient is positive for flow's dimensions: interest in the site and the challenges and skills, unlike the dimension of enjoyment provided by the site. Thus, we confirm some of the regression results. However, we note that $\mathrm{t}<1.96$ for the enjoyment and challenges and skills. Moreover, the direction of the relationship is positive only for the interest in the site. 
Table 10: Results of the Beta coefficient of regression between cognitive Loyalty and the state of flow

\begin{tabular}{|c|c|c|c|}
\hline $\begin{array}{c}\text { Dimensions of } \\
\text { flow state }\end{array}$ & Interest in the website & Enjoyment & Skills and challenges \\
\hline $\mathrm{B}$ & 0,416 & $-0,21$ & 0,01 \\
\hline $\mathrm{T}$ & 8,125 & $-1,415$ & 0,187 \\
\hline $\mathrm{P}$ & 0,000 & 0,678 & 0,852 \\
\hline
\end{tabular}

The regression results regarding emotional loyalty reveal that the Beta coefficient is positive for the dimensions of flow: interest in the site, enjoyment and challenges and skills. We therefore confirm the results of the regression. However, we note that $\mathrm{t}<1.96$ for the enjoyment and challenges and skills. Consequently, the direction of the relationship is positive only for the dimension: interest in the website.

Table 11: Results of the Beta coefficient of regression between Affective loyalty and the state of flow

\begin{tabular}{|c|c|c|c|}
\hline $\begin{array}{c}\text { Dimensions of } \\
\text { flow state }\end{array}$ & Interest in the website & Enjoyment & Skills and challenges \\
\hline $\mathrm{B}$ & 0,344 & 0,064 & 0,09 \\
\hline $\mathrm{T}$ & 6,553 & 1,219 & 1,71 \\
\hline $\mathrm{P}$ & 0,000 & 0,224 & 0,088 \\
\hline
\end{tabular}

As a conclusion, the hypothesis which states that flow state has an effect on loyalty to the website is confirmed. The effect is positive. The result is also confirmed by the study of Ilsever Cyr and Parent (2006). These authors asserted that the flow state leads to a positive and enthusiastic engagement and commitment to the website and an increased likelihood to revisit the site, or e-loyalty. These findings may also be useful to managers in designing the website by including imaginary, leading the web user to experiment the state of flow and to enhance the behaviors' approach: loyalty to the website.

Conclusion, implications, study limitation and future perspectives of research

Our research allowed us to test, conceptualize and confirm that the integration of imaginary in websites affects positively the behavior loyalty to the website, which affects the efficiency of corporate websites' communication. The major contribution of our research focused on numerous areas: the identification of variables that generate a better behavior's approach to the website through the integration of the imaginary; and a highlight on the positive impact of the integration of imaginary in web site in order to provide several recommendations to practitioners on how they can ensure better business communication. Therefore, this study has established a conceptualization and experimentation conducted in an area that affects several scientific disciplines: marketing, consumer psychology and information system. Indeed, in a context characterized by a tough and increasing competition, the integration of the imaginary in websites is one of the key solutions to generate positive results, favorable attitudes and behavior's approach, better profit, and better profitability.

However, our research has a limitation represented by the non-exposure of respondents to all aspects of imaginary, such 
as video games or fantasy contained in written texts. Other future research may therefore treat other aspects of the imaginary or experiment new variables in the conceptual model that may affect the

\section{References}

1. Baker, J. (1986), The role of the environment in Marketing Services: The consumer perspective in the services Challenge: Integrating for competitive advantages', The American Marketing Association, Czepeill J.A., Congram C.A. , Shanahan J. (ed)., Chicago, IC.

2. Bitner, M J. (1992), 'Servicesscapes: The impact of physical surrounding on consumers and employees', Journal of Marketing Research, 56 (2), 84-96.

3. Brett ASM, (2004), 'Using the Imagination: Consumer evoking and Thematizing of the Fantastic imaginary', Journal of consumer Research, 31 (1), 139149.

4. Castoriadis, C. (1975), L'institution imaginaire de la société, du Seuil (ed), coll. Esprit.

5. Costa, P.T. and McCrae, R.R. (1992), 'NEO PI-R professional manual', Psychological Assessment Resources, Odessa, FL.

6. Csikszentmihalyi M., (1982), 'Towards a Psychology of Optimal Experience', In Annual Review of Personality and Social Psychology, 3, 13-36.

7. Dahu, L. and Browne G. J., (2006), 'The Role of Need for Cognition and Mood in Online Flow Experience', Journal of Computer Information Systems, 46 (3), 11-17.

8. Das, S., Echambadi, R., McCardle M. and Luckett M., (2003), 'The Effects of Personality Traits on Shopping, Information Seeking and Surfing on the Web,' Marketing Letters, 14 (3), 185-202. relationship between the integration of the imaginary in websites and the state of flow, such as information processing and the time spent in browsing the website

9. Hoffman, D and Novak, TP. (1997), 'Measuring the Flow Experience among Web Users', Interval Research Corporation, 31 July 1997.

10. Hoffman, D., Novak, TP. and Duhachek, A. (2002), 'The Influence of Goal-Directed and Experiential Activities on Online Flow Experiences', Journal of Consumer Psychology, 13 (1-2), 3-16.

11. Holbrook, M B and Hirschman, E C. (1982), 'the experiential Aspects of Consumption: Consumer Fantasies, feelings, and Fun', The Journal of Consumer Research, 9 (2), 132- 140.

12. Iser, W. (1993), the fictive and the imaginary: Charting literary anthropology, Johns Hopkins University Press, Baltimore.

13. Ilsever, J , Cyr, D. and Parent, M. (2006), 'Extending models of flow and eloyalty', Journal of Information Science and Technology, 3(4), 3-22.

14. Kearney, MJ and Butcher, M. (1988), 'Weak Localization in The Quasi-OneDimensional Regime with Many Occupied Sub-Bands', Journal of Physics C: Solid State Physics 21 (13), 25-39.

15. Ladwein, R. and Ouvry, M. (2006), 'Experience vecue et representations du centre commercial', Actes des 11emes Journees de Recherche en Marketing de Bourgogne, 2-27 Novembre 2006, Bourgogne, France.

16. Luna, D and Peracchio, L A (2005), 'Sociolinguistic Effects on Code-Switched Ads Targeting Bilingual Consumers,' Journal of Advertising, 34 (2), 43-56. 
17. Oliver, R L. (1997), Satisfaction: A Behavioural Perspective on the Consumer, McGraw-Hill Education.

18. O'Reilly, C., Chatman, J., and Caldwell, D. (1991), 'People and organizational culture: A profile comparison approach to assessing person-organization fit', Academy of Management Journal, 34 (3) 487-516.

19. Pearce, J.M., Ainley, M. and Howard S. (2005) 'The Ebb and Flow of Online Learning', Computers in Human Behavior, 21 (5) 745-771.

20. Peñaloza, L. (2001), 'Consuming the American West: Animating cultural Meaning at a Stock Show and Rodeo', Journal of Consumer Research, 281 (3), 369-98.

21. Petty, RE and Cacioppo, JT., (1982), 'The Need for Cognition', Journal of Personality and Social Psychology, 42 (1), 126-131.

22. Petty, R E., Cacioppo J T. and Feng Kao C. (1984) , 'The efficient Assessment of Need for Cognition', Journal of Personality Assessment, 48 (3), 306-307.

23. Scott, LM. (1990), 'Understanding Jingles and Needledrop: A Rhetorical Approach to
Music in Advertising', Journal of Consumer Research, 17 (2), 223-36.

24. Sherry, J. (1990) 'A Sociocultural Analysis of a Midwestern Flea Market', Journal of Consumer Research, 17 (1), 13-30.

25. Thomas, G. (1998) 'The Myth of Rational Research,' British Educational Research Journal, 24 (2), 141-161.

\section{Copyright Notice}

Authors who publish in any IBIMA Publishing open access journal retain the copyright of their work under a Creative Commons Attribution 3.0 Unported License, which allows the unrestricted use, distribution, and reproduction of an article in any medium, provided that the original work is properly cited. No permission is required from the authors or the publishers. While authors retain copyright of their work with first publication rights granted to IBIMA Publishing, authors are required to transfer copyrights associated with commercial use to this Publisher. Revenues produced from commercial sales and distribution of published articles are used to maintain reduced publication fees and charges. 